\title{
РОЛЬ ЛЕКСИКИ В ФОРМИРОВАНИИ ЛИЧНОСТИ И НАЦИОНАЛЬНОГО ХАРАКТЕРА
}

\author{
Доц. д-р Гендрик Петкевич \\ Литовский эдукологический университет
}

\begin{abstract}
Аннотация. Особенностью современного публичного речевого общения является его диалогизированность, это вызывает большое количество проблем при переводе информации с одного языка на другой. Переводчики знают, что абсолютно точный перевод невозможен из-за разных картин мира, создаваемых разными языками. Лексический состав играет основную роль в реализации функции языка, как части культуры и средства формирования личности. В воспитании личности задействованы все языковые ресурсы, которые человек, как правило, даже не осознает.

Каждый национальный язык не только отражает, но и формирует национальный характер. Другими словами, можно сказать, что, если язык формирует представителя народа - носителя языка, причем формирует его как личность, то он должен играть такую же конструктивную роль и в формировании национального характера. Очевидно, что основную культурную нагрузку несет лексика. Из слов и словосочетаний складывается языковая картина мира, определяющая восприятие мира носителями данного языка. Преподавателю русского языка при обучении иностранных студентов важно установить эту связь между типом мировосприятия русских и изучаемыми языковыми явлениями.
\end{abstract}

Ключевые слова: язык и его преподавание, культура, коммуникация, личность, национальный характер, лексика.

\section{Вводная часть}

Французский этнограф, социолог и культуролог Клод Леви-Строс предрекал, что XXI век будет веком коммуникации или его не будет вовсе. Мы являемся свидетелями точности его понимания вызова времени. Его высказывание можно воспринимать как приглашение к принятию определенного стиля жизни и способа действия или призыв к организации нашей жизни с непременной добавкой: «плюс коммуникация». Как и многие другие виды человеческих занятий, коммуникация в нынешнее время теряет свою наивность и стихийность. Теперь она по большей части становится планируемым, организуемым, целенаправленным делом, требующим от каждого из нас умения и специальных знаний. При коммуникации, в общении друг с другом люди 
могут использовать разные каналы связи: оптический (зрительный), звуковой, тактильный (например, похлопывание по плечу или поглаживание по щеке) и т.д. Коммуникация может быть непосредственной, прямой, как при общении лицом к лицу (face to face), так и опосредованной, предполагающей использование тех или иных технических средств для передачи и приема сигналов (звонок на занятия, уличный светофор, телефон, радио, телевидение, интернет с его электронной почтой, группами новостей, видеоконференциями и пр.). Сегодня обычным явлением стала многоканальная (мультимедийная) коммуникация (кино, телевидение, интернет, компьютерные игры). Но все же господствующая роль в человеческом общении принадлежит языковой (или речевой) коммуникации.

Ни для кого не будет секретом и то, что хорошее владение иностранным языком способно существенно помочь в жизни. Человек, хорошо владеющий иностранными языками, сможет воспринимать гораздо больше важной для него информации. Кроме того, знание иностранных языков открывает путь в мир интересных людей, где грамотный человек сможет удивить и порадовать любого своим интеллектом и познаниями. Вершиной совершенства владения иностранным языком считается тот момент, когда при общении с носителем другого языка тот даже не догадывается, что его собеседник на самом деле является иностранцем.

Знание иностранных языков очень пригодится тем людям, которых волнует постоянный карьерный рост. Сегодня практически каждый, кто хочет добиться успеха в жизни и выбранной сфере деятельности, хорошо понимает, как важно знание иностранных языков. Современные работодатели выдвигают достаточно высокие требования к соискателям и практически в любой компании начальными требованиями являются такие, как умение работать с персональным компьютером и знание иностранного языка. Владение в совершенстве несколькими иностранными языками в значительной степени повышает шанс найти высокооплачиваемую перспективную работу с возможностью быстрого карьерного роста.

Отметим и тот факт, что у всех людей вне зависимости от пола и стиля жизни есть свои собственные интересы и увлечения. Можно увлекаться музыкой, компьютерами, туризмом, коллекционированием, цветоводством, пчеловодством и т.д. В современном мире такие средства как интернет, телевидение и пресса дают практически безграничные возможности увлеченным людям для получения информации. Единственная особенность заключается в том, что большинство этой информации на иностранном языке. Именно поэтому для расширения и реализации своих интересов достаточно часто людям также приходится изучать иностранные языки.

Современная речевая ситуация характеризуется и вовлечением широких слоев населения в публичную речь, разнообразием ее родов (политическая, военная, дипломатическая, академическая, церковная, деловая) и жан- 
ров (лекция, доклад, проповедь, выступление на митинге, в публичной дискуссии и др.). Особенностью современного публичного речевого общения является его диалогизированность: на передний план выступают различные формы диалога (спор, дискуссия, полемика, теледебаты, интервью), нередко опосредованного средствами массовой информации. При такой диалогизированности речевого общения возникает большое количество проблем при переводе информации с одного языка на другой. Переводчики знают, что абсолютно точный перевод невозможен из-за разных картин мира, создаваемых разными языками. Бахтин говорил, что слово пахнет контекстами. Вот этот «запах» тоже часто теряется при переводе. Ведь картина мира - это «вся сумма, вся система представлений о мире, рожденных социальным опытом и биологическим статусом человека, нации, человечества. <..> Картина мира воплощает и сохраняет себя в системе текстов» [Федоров, 2004]. Последний тезис чрезвычайно важен для фольклористов, этнологов, историков культуры и лингвистов, поскольку отношение человека к миру как единая упорядоченная система взглядов прямо или опосредованно реализуется в мифологии, философии, народных верованиях, обычаях и обрядах и, конечно, языке.

Наиболее частым случаем языкового несоответствия является отсутствие точного эквивалента для выражения того или иного понятия, и даже отсутствие самого понятия. Это связано с тем, что понятия или предметы, обозначаемые такими словами, являются уникальными для данной культуры, а в других культурах отсутствуют и, следовательно, там нет соответствующих слов для их выражения. Так, в русском языке нет эля или виски, а значит, нет и соответствующих слов на русском языке (было бы смешно говорить вместо этих слов - нехмельной напиток и самогон). А в английском языке «нет слов» для блинов, борщза, водки и т.д. Вспомним еще один интересный факт, что русское слово собутыльник можно перевести на немецкий язык только описательно: человек, который употребляет спиртное вместе с вами. А русским синонимам типа: пьяница - алкоголик, бухарик, алкаш, алконавт, пропойца, хроник, баклажан, синюга т.д. соответствует в немецком языке всего лишь одно слово trinksuechtig. Более сложным случаем оказывается ситуация, когда одно и то же понятие по-разному - избыточно или недостаточно - выражается в разных языках. Поэтому победу можно только одержать, роль - играть, значение - иметь. Русский крепкий чай по-английски будет сильным чаем (strong tea), а сильный дождь - тяжельм дождем (heavy rain). В разных языках есть много устойчивых выражений со словом нос. В русском языке - зарубить на носу (крепко запомнить); в немецком - Eine Nase geben (nожурить; буквально, дать в нос); в английском - to pay through the nose (вынужденно платить втридорога; буквально: платить сквозь нос); во французском - se manger le nez (спорить до умопомрачения; буквально: cъесть себе нос) или La moustarde lui monte au nеz (его охватил гнев; буквально: горчица бросилась ему в нос); в итальянском - non ricordaredella bocca al naso (ничего не помнить; 
буквально: не помнить от рта до носа). Это примеры лексико-фразеологической сочетаемости слов, которые естественны и привычны в родном языке, но совершенно непонятны для иностранца (если он будет переводить эти словосочетания по словарю). Можно окончательно запутаться, если еще вспомнить, что помимо проблем с лексико-фразеологической сочетаемостью слов существует конфликт между культурными представлениями разных народов о тех предметах и явлениях реальности, которые обозначены эквивалентными словами этих языков. Эти культурные представления обычно определяют появление различных стилистических коннотаций у слов разных языков. Примером может служить словосочетание зеленые глаза, которое по-русски звучит весьма поэтично, наводит на мысли о колдовских глазах. Но то же самое словосочетание по-английски (green eyes) напоминает о зависти и ревности, которые были названы Шекспиром в его трагедии «Отелло» «зеленоглазым чудовищем». Если в России встретить черную кошку - к несчастью, то в Англии - к удаче. В русском языке слово яма обозначает углубление, а в японском слово с таким же звучанием обозначает гора. Название самой высокой горы в Японии Фудзиямы так и преводится - гора Фудзи.

Работая в нашей, литовской, аудитории таких примеров мы можем привести ни один десяток. Вспомним, как трудно объяснить обычное слово пляcкa: отталкиваемся от слова šokis, сверяемся со словарями и получаем - maнец. Но каждому носителю русского языка как родного известно, что пляска носит импровизационный характер, в первоначальном своем происхождении сводится к свободному выражению охватывающих человека сильных ощущений: радости, гнева, любовной страсти, веселья и т.д. Литераторы также в своей практике сталкиваются с подобными трудностями. Чего стоит перевод названия известного романа Андрея Платонова «Котлован» на литовский язык - «Duobė» («Яма»!?). Отметим, что слово яма в XIII в. использовалось со значением общая могила, с XV в. - подземная тюрьма. А чего стоят выражения - долговая яма, оказаться в яме, выгребная яма и т.д. Котлован - улубление в земле, предназначенное для закладки фундамента каких-либо сооружений, - сразу же ассоциирует со словами фундамент, держать, мощз, нагрузка, нести. Исходя даже из этих примеров, можно убедиться в том, как важно правильно определиться при выборе методики обучения языку.

\section{Основная часть}

Любая методика обучения языку как иностранному представляет собой педагогическую дисциплину не только о законах и правилах обучения языку, но и способах овладения этим языком, а также об особенностях образования и воспитания средствами языка. Как писал российский психолог и лингвист А. Леонтьев о методике обучения русскому языку, «предмет методики обучения русскому языку как иностранному - оптимальная система управления 
учебным процессом, т.е. система, направленная на наиболее эффективное овладение русским языком» [Леонтьев, 1988: 35]. При обучении русскому языку нам в первую очередь необходимо помнить, что между культурами двух стран имеется существенная разница.

Наука этнолингвистика утверждает, что именно в лексике отражается национальный характер. Но прежде, чем говорить о динамике русского национального характера, коснемся постоянно обсуждаемой в научных прениях, политических дебатах, на интернетных страницах, в публицистических заметках проблемы сущности национального характера (в частности, русского), как некоего социально-психологического феномена, обладающего совокупностью устойчивых признаков. В разных источниках, в многочисленных работах по этнопсихологии, культурологии, социальной философии весьма различно определяются объем и структура понятия «национальный характер», по-разному соотносится данное понятие с такими понятиями, как «культурный архетип», «менталитет» («ментальность»). Чрезвычайно щироким является разброс при определении количества и состава типичных черт русского национального характера, перечисления среди них положительных и отрицательных. Так, авторитетный академик Д.С. Лихачев в качестве важнейших называет такие черты русского характера, как свобода личности, терпение, «стремление во всем доходить до крайностей, до пределов возможного» [Лихачев, 1990: 5]. Многие авторы отмечают противоречивость (амбивалентность) русского характера. Известный российский лингвист А.Д. Шмелев пишет «о широте русской души», подтверждая это ее качество убедительным лингвистическим анализом ряда самобытных слов русского языка, таких как тоска, удаль, воля, простор [Шмелев, Интернет]. Любопытно отметить, что в обсуждении проблемы и оценке русского характера активно принимают участие и зарубежные ученые. В частности, китайский лингвист Сун Яньвэй, анализируя пословицы и поговорки русского языка, выделяет следующие «типичные черты русского национального характера»: трудолюбие, одарённость, свободолюбие, силу воли, мужество, терпение и стойкость, гостеприимство, иироту натуры, религиозность [Сун Яньвэй, Интернет].

Разные черты в русском национальном характере - то положительные, то отрицательные - выделяют, как уже упоминалось, и участники различных методических форумов в Интернете, научных конференций, круглых столов и радиопередач.

Так, автор и ведущая рубрики о русском языке на Радио Свобода Лиля Пальвелева посвятила целый выпуск теме русского языка, национального характера и языковой картины мира [Пальвелева, Интернет]. Ирина Левонтина, старший научный сотрудник Института русского языка имени Виноградова Российской академии наук, которая участвовала в это беседе, считает, что в языке выражаются определенные представления об устройстве жизни, которые различаются у представителей разных народов. «В совокупность 
этих представлений об устройстве жизни входят и так называемые этностереотипы, которые выражаются, в частности, - самое простое - в сочетаемости обозначений того или иного качества, скажем, со словом русский» [Пальвелева, Интернет]. Ведущая и гостья передачи коснулись интересной лингвистической статьи «С чисто русской аккуратностью» [Плунгян и Рахилина, 1996: 340-351]. Суть статьи, состоит в том, что, действительно, сочетание «русская аккуратность», по мнению авторов, звучит смешно по-русски, хотя, естественно, никто не думает, что русские неаккуратные люди. Но, тем не менее, «немецкая аккуратность» звучала бы естественно, а «русская аккуратность» звучит смешно, потому что в совокупность таких представлений о фундаментальных качествах русского человека аккуратность не входит. Чаще говорят русская бесшабашность, русская удаль, русская щедрость, русское гостеприимство и хлебосольство. Далее определяя, что есть русский характер и как он отражается в каких-то чисто русских словах, И. Левонтина утверждает, что представления о нации, как едином организме, и о существовании национального характера возникли достаточно поздно - во второй половине XVIII века. А уже в начале XIX века можно было прочитать о том, что вот русский национальный характер проявляется именно в специфических словах. В русской литературе первое упоминание понятия «национальный характер» связано с Екатериной II. Когда ее спросили, в чем состоит русский национальный характер,стала говорить что-то насчет высоких моральных качеств и утверждать, что русский национальный характер состоит в «скором и быстром приятии всего». Что касаемо «русских слов», то ученый-лингвист остановилась на слове простор как специфически русском слове. Действительно, слово простор - непросто переводимое слово, в отличие от слова пространство, которое легко переводится на другие языки. Что же в нем такого специфического? Если пространство трехмерно, то простор - это скорее на плоскости: большие расстояния во все стороны. При этом простор связан с волей, отсутствием стеснений. Нужно для жизни большое расстояние, чтобы можно было гулять - разгуляться на воле. В русском языке есть еще много других слов, выражающих «большие расстояния»- иирь, даль, приволье, раздолье, очень много и прилагательных - бескрайний, безграничный, безбрежный.

В среде филологов весьма популярна и часто цитируема книга известного российского лингвиста, доктора филологических наук, профессора МГУ имени М.В. Ломоносова С.Г. Тер-Минасовой «Язык и межкультурная коммуникация». Эта книга посвящена одному из аспектов бурно развивающейся во всем мире науки культурологии, а именно - лингвистическому. В центре внимания автора оказывается взаимодействие языков и культур, проблемы человеческого общения, межкультурной коммуникации, где главным средством был и остается язык.

Материал в пособии излагается настолько увлекательно, с конкретными примерами, что книга доступна и «широкому читателю». В одном из разделов 
автор рассматривает вопросы соотношения языка и человека, подчеркивая, что язык и человек неразделимы. Язык не существует вне человека, и человек как homo sapiens не существует вне языка. Соответственно, человека нельзя изучать вне языка, и язык нельзя изучать вне человека. Язык отражает окружающий человека мир, созданную им культуру, хранит ее для человека и передает ее от человека к человеку, от родителей к детям. Язык - орудие познания, с помощью которого человек познает мир и культуру. Наконец, язык - это орудие культуры: он формирует человека, определяет его поведение, образ жизни, мировоззрение, менталитет, национальный характер, идеологию. Язык - «строгий и неподкупный учитель, он навязывает заложенные в нем идеи, представления, модели культурного восприятия и поведения. В какомто смысле человек раб своего родного языка: он с младенчества попадает под влияние и власть языка родителей и вместе с языком усваивает хранящуюся в нем культуру того речевого коллектива, членом которого он совершенно случайно, не имея никакого выбора, оказался» [Тер-Минасова, Интернет]. Человек родился и с первой минуты слышит звуки своего будущего родного языка. Язык знакомит его с окружающим миром, навязывая ему то видение, ту картину, которую «нарисовали» до него и без него. Одновременно через язык человек получает представление о мире и обществе, членом которого он стал, о его культуре, то есть о правилах общежития, о системе ценностей, морали, поведении и т.п. Язык отражает мир и культуру и формирует носителей языка. В книге на материале русского и английского языков рассматривается, каким образом язык формирует личность, к каким разнообразным средствам из своего арсенала он для этого прибегает. При этом, акцентируется, человек не осознает той активной роли, которую язык играет в формировании его (человека) характера, поведения, отношения к жизни, отношения к людям и т.п. Через наглядные примеры (стереотипы, различные фольклорные и художественные тексты) профессор Тер-Минасова подводит читателя к выводам, что каждый национальный язык не только отражает, но и формирует национальный характер. Иначе говоря, если язык формирует представителя народа - носителя языка, причем формирует его как личность, то он должен играть такую же конструктивную роль и в формировании национального характера.

Очевидно, что основную культурную нагрузку несет лексика. Из слов и словосочетанийх складывается языковая картина мира, определяющая восприятие мира носителями данного языка. Особенно наглядно и ярко этот аспект представлен «устойчивыми выражениями, фразеологизмами, идиомами, пословицами, поговорками - то есть тем слоем языка, в котором непосредственно сосредоточена народная мудрость или, вернее, результаты культурного опыта народа» [Тер-Минасова, Интернет]. Количество и качество идиом, отражающих положительную или отрицательную оценку тех или иных человеческих качеств, можно считать показателем этических норм, правил социальной жизни и поведения в обществе, отношения нации через ее 
культуру и язык к миру, другим народам и культурам. Грамматические особенности русского языка также требуют особого подхода, так как при переводе могут возникнуть «непреодолимые» трудности. Сошлемся лишь на один пример, представленный в пособии. Трудно представить себе, что русское слово старушка в есенинском «Ты жива еще, моя старушка?» требует в переводе четырех (!) английских слов: «Are you still alive, my dear little old woman?» Действительно, по-русски можно сказать о людях: Машенька, Машутка, Мaшуня, Машунечка и т.д.; девушка, девочка, девонька, девчушка, девчонка, девчоночка; о животных: кот, котик, коток, котишка, котишечка, котишенька; а также о любом предмете неживого мира: домик, домишечка, домичек, домок, домушка; ложечка, вилочка, кастрюлька, сковородочка и т.д. Всему этому богатству английский язык может противопоставить только слово little или dear little: little cat [букв. маленькая кошка], dear little dog [букв. милая маленькая собака], но до dear little fork/spoon/frying pan [букв. милая маленькая вилка/ ложка/сковорода] англоязычному человеку трудно добраться. И еще немного о «скучной» грамматике: в русском языке, при относительно свободном порядке слов, падежные окончания сразу покажут, кто кого любит - Петя Катю или Катя Петю, независимо от места слов в предложениях: Катя любит Петю; Петю любит Катя; Петю Катя любит; Любит Петю Катя; Любит Катя Петю. В английском языке, имеющем форму Катя любит Петя (Kate loves Pete), кто первый - тот подлежащее, тот и совершает действие.

Загадку русской души пытаются разгадать и зарубежные лингвисты. Упоминаемый выше Сун Яньвей из Даляньского университета (Китай) уверен, что национальный характер отражается как в художественной литературе, философии, публицистике, искусстве, так и в языке. Ибо язык - зеркало культуры, в нем отображен не только реальный мир, окружающий человека, не только реальные условия его жизни, но и общественное самосознание народа, его менталитет, национальный характер, образ жизни, традиции, обычаи, мораль, система ценностей, мироощущение, видение мира. Поэтому язык должен изучаться в неразрывном единстве с миром и культурой народа, говорящего на данном языке. Автор останавливается на типичных (положительных) чертах русского народа: трудолюбии, свободолюбии, религиозности, терпении, гостеприимстве и др. Все черты характера анализируется через лексику фольклорных жанров (пословиц и поговорок).

Действительно, многие филологи в своих работах указывают на то, что именно пословицы отражают менталитет народа, в них выражается непосредственная оценка жизни. Пословицей становится выражение, которое согласовалось с образом жизни и с мыслями множества людей. Пословицы справедливо считаются концентрированным отражением народного опыта, который хранится в языке и передается из поколения в поколение. Поэтому во многих работах наибольшее внимание уделяется именно данной части лексического слоя языка. 
Национальный язык является одним из ресурсов, хранящих в себе культуру народа. Менталитет и особенности языка влияют друг на друга. Язык подтверждает существование национального характера и хранит то, что можно назвать интеллектуально-духовными генами, которые переходят из поколения в поколение, отражая и развивая черты национального характера. Мы же в преподавании языков (и в частности русского) порой забываем этот аспект работы. Порой все-таки стоит вспомнить метод известного российского культуролога Георгия Гачева - космософия (Мудрость Космоса). Г. Гачев утверждал, что у каждого народа есть свой национальный Космос, который составляют тип местной природы (при- - рядом, около, близко и род - родина, родня, родственник и т.д.), национальный характер и склад мышления. А все это напрямую связано с языком, его лексикой. Филологи со студенческой скамьи помнят, как в стихах С. Есенина красота девушки часто сравнивается с красотой березки, типичного для российских просторов дерева: Я навек за туманы и росы / Полюбил у березки стан / и ее золотистые косы, / И холщовый ее сарафан. / Потому так и сердиу не жестко - / Мне за песнею и за вином / Показалась ты той березкой, / Что стоит под родным окном. А поэты Индии сравнивают своих красавиц с коровами, и девушки, естественно, не находят в этом ничего оскорбительного.

\section{Вывод}

В наше время проблемы межкультурной коммуникации являются одними из самых сложных и требующих постоянного внимания. Именно в диалоге представителей разных культур обнаруживается как сходство, подобие, так и различие, а порой полная противоположность национальных менталитетов. Ментальные особенности проявляются в языке, его грамматическом строе, его категориях и формах. При обучении иностранных студентов русскому языку нужно устанавливать связи между типом мировосприятия и мышления русских и изучаемыми языковыми явлениями.

Как видим из статьи преподавателям-лингвистам необходимо учитывать разницу в особенностях мышления разных народов. Если говорить о европейцах, то «русские сильны в синтезе, ... а западные люди - в анализе» [Колесов, 2013: 58], то есть в разграничении явлений и противопоставлении их. При выражении универсальных категорий мышления русский язык «озабочен сходствами и подобиями, погруженными в психологические сферы» [Колесов, 2013: 56]. Именно такой синергийный принцип мышления русских приводит к развитой языковой полисемии. Поэтому на занятиях по русскому языку при толковании слов нужно соотносить объём понятия в русском языке с объёмом понятий в языке иностранных учащихся и в языке-посреднике.

Многочисленные примеры убеждают нас в том, что на занятиях по изучению русского языка как иностранного необходимо представлять лексиче- 
ские ряды, грамматические модели и формы как определенный ментальный код. Именно такой способ подачи языкового материала дает студентам новую мотивацию в изучении языка [Акишина, Каган, 2010: 174-191], делает процесс обучения иностранному языку увлекательным, подготавливает студентов к более глубокому пониманию языка и особенностей ментальности русских.

\section{Литература}

1. Акишина, А.А., Каган, О.Е. (2010). Учимся учиться. Для преподавателя русского языка как иностранного. Москва, 256 с.

2. Гачев, Г. (2015). Космо-Психо-Логос. Национальные образы мира. Москва: Академический проект, 512 с.

3. Гачев, Г. (2008). Ментальности народов мира.Москва: Эксмо, 544 с.

4. Колесов, В.В. (2013). Язык и ментальность: сравнение европейских менталитетов. Русский язык за рубежсом. N5. C.55 - 62.

5. Леонтьев, А.А. (1988). Методика. Заочный курс повышения квалификации филологов-русистов. Москва, С.24-37.

6. Лихачев, Д.С. (1990). О национальном характере русских. Bonpocbl философии, N 4. С. 3-6.

7. Пальвелева, Лиля (2006). Русский язык и национальный характер. [Žiūrèta 2015-10-12] http://www.svoboda.org/a/158532.

8. Плунгян, В.А., Рахилина, Е.В. (1996). «С чисто русской аккуратностью»: к вопросу об отражении некоторых стереотипов в языке. Московский лингвистический журнал. Том 2. С. $340-351$.

9. Тер-Минасова, С.Г. Язык и межкультурная коммуникация. [Žiūrèta 2015-10-17] http://www.gumer.info/bibliotek_Buks/Linguist/Ter/_Index.php.

10. Сун, Яньвэй. Типичные черты русского национального характера и их отражение в русских пословицах и поговорках. [Žiūrèta 2015-10-07] http://x.info/readarticle.php?article_id.

11. Федоров, Ф.П. (2004). Художественный мир немецкого романтизма: Структура и семантика. Москва: МИК, 368 с.

12. Шмелев, А.Д. Широта русской души.. [Žiūrèta 2015-10-07] http://lib.ru/CULTURE/SHMELEW_A/shirota.txt. 


\title{
THE ROLE OF VOCABULARY IN PERSONALITY AND NATIONAL CHARACTER FORMING
}

\author{
Assoc. Prof. Dr. Gendrik Petkevič \\ Lithuanian University of Educational Sciences
}

\section{Summary}

A special feature of modern public verbal communication is its dialogic nature. It causes a large quantity of problems with the translation of information from one language into another. Translators and interpreters know pretty well that it is impossible to produce a precise translation because of different world pictures, which exist in different languages. The most frequent case of lingual nonconformity is the absence of a precise equivalent to express and name some concepts or objects and sometimes even lack of a concept in one language and its existence in another. It is connected with the fact that the concepts denominated with such words are unique for a certain culture and there are no such concepts and objects in other cultures at all. So, as a result, there are no appropriate words to denominate these concepts in these languages.

A foreign language cannot be learned without learning of the people speaking this language. Any language reflects human world and people's culture. A language saves national culture and passes it on from one man to another, from parents to children. A language is an instrument of cognition, with the help of which a man gets known with the world and culture. Finally, a language is a tool of culture: it creates a man, determines his behaviour, the way of his living, world outlook, mentality, national character and ideology. Every national language not only reflects but also generates national character. In other words, we can say that if a language creates a representative of a nation (native speakers) and generates his personality, it must play the same constructive role in the creation of national character. Obviously, vocabulary bears the main cultural load. The lingual world picture, which determines the perception of the world, is built with words and word combinations. And precisely lexical fund plays the dominant role in the realization of the language function as a part of culture and as an instrument of the formation of personality. All language resources are used when we are dealing with an education of a personality. As a rule, a person does not even realize this fact. When teaching foreign students, it is important for a Russian teacher to establish a connection between the type of perception of the world by Russians and the language phenomena.

Key words: foreign language learning, culture, vocabulary, personality, national character, lingual world picture 


\section{AUTORIAUS LYDRAŠTIS}

Autoriaus vardas, pavardè: Gendrik Petkevič

Mokslo vardas ir vardas: humanitarinių mokslų daktaras, docentas

Darbo vieta ir pareigos: Lietuvos edukologijos universiteto Rusų kalbos ir kultūros studijų centro direktorius

Autoriaus mokslinių interesų sritys: komparatyvistika, tautosaka

Telefonas ir el. pašto adresas: 860710 983, gendrik.petkevic@leu.lt

\section{AUTHOR'S COVER LETTER}

Author's name and surname: Gendrik Petkevič

Academic degree and name: Associate Professor, Doctor

Workplace and position: Lithuanian University of Educational Sciences, Russian Language and Culture Study Centre, Director

Author's research interests: comparativistics, folklore

Telephone and e-mail address: +370 60710 983, gendrik.petkevic@leu.lt 